\title{
SOBRE EL CONCEPTO Y LA EVOLUCIÓN DE LA FRONTERA EN LOS REINOS HISPÁNICOS PENINSULARES. ENTRE ÚBEDA Y SEPÚLVEDA
}

\author{
Antonio LINAGE CONDE \\ Adela TARIFA FERNÁNDEZ
}

\section{LA FRONTERA}

A propósito de la acuñación de los Estados Unidos se ha insistido en que la clave de «la sencillez rústica, pero sólida y auténtica de su vida de frontera», una frontera cuyo desplazamiento iba "conformando y cargando, en su avance, individualismo, democracia y nacionalismo»' ${ }^{1}$. Opinión que aquí traemos a introductoria colación, pese a su lejanía geográfica y la tan distinta circunstancia vital de nuestra España medieval, para sentar desde un principio el convencimiento que tenemos de haber sido igualmente la frontera, configurada y modificada ésta al lentísimo paso de la Reconquista, el elemento decisivo de nuestro paralelo hacerse.

Frontera junto a la cual hay que considerar decisivamente la faja desértica ubicada, simplificando por la historiografía predominante, en el valle del Duero; pero que puede extenderse, sin pérdida de contacto con la realidad, de Oporto a Barcelona. Una tierra de nadie que se ha llamado desierto estratégico, epíteto que no es posible aceptar sin someterlo a alguna reflexión. Por cuya vía habremos ineludiblemente de encontrarnos la cuestión de su posible índole fronteriza en sentido amplio, sus conexiones con la frontera en todo caso. Dentro de esa su índole determinante para captar la entraña del moldearse hispano que confesó en él don Claudio Sánchez Albornoz al justificar la oceánica desmesura de su respuesta a la negación desdeñosa,

1 Cfr. R.F. LAFUENTE, sobre La cultura de la queja, de Robert Hughes, ABC literario, núm. 137, 17-6-1994, p. 14. 
un tanto hecha de pasada por don Ramón Menéndez Pidal², a la búsqueda de ese «secreto de los grandes problemas españoles» que Ortega y Gasset no pudo por menos de radicar en la Edad Media ${ }^{3}$.

De 1846 a 1853 publicó Alejandro Herculano su Historia de Portugal ${ }^{4}$, lanzando en ella como novedad su visión del desierto medieval del Duero. A pesar de lo cual, los historiadores que siguieron no insistieron apenas en la sugerencia, hasta el apuntalamiento, desde luego el más decisivo de los suyos, del propio Sánchez-Albornoz, ya en 1966, en el crepúsculo de su exilio bonaerense. Con un apoyo sólido en el interludio, el del bibliotecario bordelés de la Sorbona, excesivamente crítico con los papeles de este lado de los Pirineos, Louis Barrau-Dihigo, nacido en 1876, un año antes de que el historiador lusitano muriera solitario en su quinta del Valle de Lobos. En 1921 publicaría aquél sus Recherches sur I'histoire politique du royaume asturien, $718-910^{5}$.

Sin embargo, Diego de Colmenares, en su Historia de la insigne ciudad de Segovia y compendio de las historias de Castilla, aludía en $1637^{6}$, si bien para manifestar su disconformidad, a "lo que en nuestros tiempos se ha escrito" inadvertidamente de que nuestra ciudad y su comarca estaba desierta por esos años".

Así las cosas, calibrar el grado de densidad desertizante de la población que quedó, no nos compete aquí. Sino matizar si el desierto fue o no en alguna medida frontera.

\section{DE LA DESPOBLACIÓN A LA REPOBLACIÓN}

Siendo ante todo preciso distinguir entre la etapa desertizada y la del poblamiento inicial.

Durante la primera, el panorama demográfico no era otro que el de grupos de pastores con algunos labradores y los consabidos ermitaños en los reductos predestinados a la geografía monástica.

Cuando la repoblación comienza ya es otro cantar. $Y$ notemos que a veces ese inicio, aparte de ser débil en sí, se dejaba atrás una buena porción de tierra que se-

2 Despoblación y repoblación del valle del Duero, Buenos Aires, 1966.

3 Sin perjuicio de la posible discusión fecunda de las consideraciones de éste acerca de "la anormalidad permanente de la historia española» — «ensaye quien quiera la lectura paralela de nuestras crónicas medievales y las francesas»- y sobre todo la definición con la cual concluye de haber sido «la historia de España entera, y salvo fugaces jornadas, la historia de una decadencia». Posteriormente citaremos los pasajes concretos orteguianos de donde están tomadas estas referencias.

4 Véase $5^{\text {a }}$ edición, III, 1891, p. 183.

5 «Revue Hispanique»52, 144; tirada aparte el mismo año en Tours.

6 Ed. Academia de San Quirce de Segovia, 1969, I, 12, pp. 195-6.

7 Basa su disconformidad en la confusión de lo reivindicatorio - límites del obispado de Simancas, cuyo titular, Ilderedo, se titulaba de Segovia, pero sólo lo podía ser in partibus (véase nuestra noticia sobre él en «Dictionnaire d'histoire et géographie ecclésiastiques»)- y lo real. Sobre donde pudo haberse escrito «inadvertidamente» el asunto del desierto, damos importancia a la oralidad. Eran bien escasos los medios de difusión gráfica, y no superarían el peso de aquella. 
guía eremada. Pensemos en la de Sepúlveda, por Fernán González, el año 940, que por eso fray Justo Pérez de Urbel la llamó salto de tigre. En esas circunstancias, a la tierra de nadie sucedió otra que ya empezaba a tener dueños, pero bajo la espada de Damocles de la inseguridad. $Y$ entonces es cuando se habla de guerreros - 0 caballeros - pastores y aparecen fortificaciones plantadas en la inmensidad poco ha vacía y ahora sólo con islotes en lucha por el arraigo ${ }^{8}$. Así las cosas, diríamos que esta tierra tendente a la vuelta a la vida suplantaba a la frontera, al fin y al cabo hacía sus veces «los dos se mantuvieron en el yermo o desierto que hay entre las comarcas musulmanas y cristianas», según rezaba Ibn Al-Qûtîya ${ }^{9}$.

Pero lo cierto es, que tanto una como otra situación pueden tildarse de antifronterizas. Un paisaje histórico que sería elocuente cotejar con el de los territorios europeos de dispares destinos entonces y hasta el futuro lejano.

\section{EN POS DE LA CLAVE}

Los que tuvimos como tierra nativa la de Sepúlveda, ya antes de conocer la hipótesis de la despoblación, en la niñez, notábamos la intuición de un vacio inexplicado, vislumbrado sólo a medias; de manera que, el tener noticia de aquella, sensorialmente nos pereció como si las piezas de un rompecabezas se acoplaban.

Mas, ¿sería lícito inquirir algún significado?

Para Ortega y Gasset, la falta o debilidad del feudalismo en España, el equivalente de "las minorías de superior intelecto" en las sociedades modernas, dio lugar a la formación de reinos con monarca y plebe -ésta, entre otras incapacidades, aquejada de la de organizar un estado de prolongada consistencia- pero sin suficiente número de nobles; y por esos caminos llegó a sostener que no hubo verdadera Reconquista, al contrario de otras partes en que hubo Cruzadas $^{10}$. A propósito de esta preterición de la Reconquista se nos ocurre sin embargo, de momento, objetar que precisamente lo larguísimo de su duración, si bien no fue incompatible con la continuidad de la lucha por la fuerza misma de las cosas, tiene también otra vertiente, de persistencia en el propósito de imponer la civilización propia, una recuperación en este caso de la España perdida.

Pero, ya en nuestro argumento, esas reflexiones que el genial pensador y literato empezó a escribir en El Sol el año 1920, su España invertebrada, ¿no habrían podido aplicarse a la falta de frontera, y al desierto de ella causante, acaso en una relación de causalidad más íntima con la invertebración postulada?

8 L.M. VILLAR GARCÍA, La Extremadura castellano-leonesa. Guerreros, clérigos y campesinos, 711-1252 (Valladolid, 1986); D. CONTE BRAGADO, Introducción a la arqueología del cañón del Duratón (Segovia, 1993), 181-94.

9 Versión de J. RIVERA, Colección de obras arábigas de historia y geografía (Academia de la Historia) 1, p. 74.

10 Texto en «Obras Completas» (6⿳a ed., Madrid, 1966) 3, pp. 109-12.

11 Tal como, por ejemplo, la reconstruye M. MARTÍNEZ MARTÍNEZ, «Organización y evolución de una sociedad de frontera: el reino de Murcia, ss. XIII-XIV», Medievalismo 5 (1995) 31-88. 
Lo cierto es que en el septentrión, la presencia del desierto supliendo a la frontera, determinó luego, llegada la hora repobladora de él, la aparición de una frontera peculiar en las avanzadas de la misma, muy diversa de la que después, al sur de la tierra despoblada, iría delimitando sucesivamente ${ }^{11}$ los dominios de la cruz y de la media luna, aunque en algún caso fueran protagonistas de un nuevo poblamiento, también del todo distinto. Por lo cual precisamente, no nos parece caprichosa la repartición de estas páginas entre sendos ejemplos de ambas situaciones.

Y la caracterización de la tal frontera peculiar se produce primero acuñándose una noción jurídica de la misma.

\section{LA SIGNIFICACIÓN DEL FUERO DE SEPÚLVEDA O DE EXTREMADURA}

Al repoblar Sepúlveda, Fernán González la concedió un Fuero. Ello equivalía a darla un régimen jurídico particular, determinado por la necesidad de atraer gentes a la nueva frontera. Una frontera que ahora lo seguía siendo con el desierto, pero en una posición avanzada y peligrosa. De manera que, en la óptica de sus pobladores no podían entrar ni la convivencia ni la retirada asequible, como ocurriría después en otros puestos y lineas, entre poblaciones nada más queremos decir.

El texto del Fuero fernandino no se conserva. En el año 1076 lo confirmó Alfonso VI, de cuyo texto conservamos una copia ${ }^{12}$.

Antes y después, el Derecho de Sepúlveda se enriqueció con nuevas normas, hasta llegar a ser un ordenamiento jurídico bastante completo, que fue puesto por escrito el año 1300.

Los historiadores del Derecho venían discutiendo la precedencia cronológica entre este Fuero y otros de la misma familia, pero teniendo sólo en cuenta las redacciones escritas. Fue Rafael Gibert el que llamó la atención hacia la necesidad de tener en cuenta la elaboración consuetudinaria de las normas que posteriormente fueron escritas. De ahí que, en los preceptos sepulvedanos que integran la redacción de 1300, los tenga forzosamente que haber de datación muy diversa, por lo general precisarlo de no fácil conjetura.

Así las cosas, debemos fijarnos en el título primero titulado «que toda Extremadura sea tenida de venir a Sepúlveda a fuero", y cuyo contenido se limita a reiterar la concesión del término de la Villa a sus vecinos presentes y futuros. Pero lo que quiere decir es que se había creado un derecho de la frontera peligrosa y avanzada con el desierto, cuya acuñación fue el Fuero de Sepúlveda. De ahí la primacía de éste, con independencia de problemas redaccionales. $Y$ el dato es decisivo cual comprobante de ese peculiar concepto jurídico de la también particular frontera en cuestión.

Una situación que ¿dejó de darse absolutamente cuando unas y otras tierras limitaban fronterizamente sin la medianería del desierto?

12 E. SÁEZ y otros, Los Fueros de Sepúlveda (Segovia, 1953). 


\section{ÚBEDA ¿EN LA ÚLTIMA FRONTERA?}

Y llegados de uno a otro extremo pocos ejemplos más paradigmáticos para cuestionar concepto y significado de frontera, en el cotejo anunciado, que esta ciudad andaluza, en la «Extremadura castellana», mitad meseta-plaza, mitad borde-almena, en el castillo peninsular del medievo invertebrado. Pero nunca desierto, en el sentido humano más estricto. Porque desiertos puede haberlos de muchos tipos, y todos tiene en común esa vaga sensación de vacío antes aludida para la primera «despoblación» sepulvedana.

Aquí es obligado reiterar la transcendencia de aquella reflexión inicial: el lento paso de la Reconquista como elemento decisivo para entender nuestro pasado, y desde luego presente. Porque ¿es acaso tangencial que a la hora del cotejo en la repoblación cristiana de estas dos Extremaduras hayan transcurrido casi dos siglos? Con todo lo que el paso del tiempo trajo para unos y otros, transmutados destinos de vencedores en vencidos.

Así el privilegio de ejercitar la visión retrospectiva que es concedido al historiador permite constatar a la vuelta de cada meandro que nada fue ni será definitivo cuando lo construyen hombres, inexactos por definición. Mutables infinitamente, en la aparente inmutabilidad en que el tópico suele envolver desde el desconocimiento a los siglos más remotos del medievo hispano.

Notemos pues que el «desierto» se convierte en elemento diferencial aparente: es el exceso de ocupación humana en la vieja Ebbdete mora el principal problema de los monarcas cristianos. Es la falta de repobladores cristinos, a la inversa, lo que retrasa más de un siglo su definitiva conquista, fracasadas una y otra vez desde el reinado de Alfonso $\mathrm{VI}$, por más que las crónicas cristianas del momento adornen el valor épico de sus guerreros, las avanzadillas sobre lo que era ya populoso núcleo urbano de la media luna ${ }^{13}$. ¿Cómo entender sino, ejemplificando lo más notable, que tras la gloriosa «... batalla que llamaron de las Navas de Tolosa, y también de Úbeda, por haber tenido principio en aquellas y fin en ésta...", cuando los cristianos asolan la villa, pasando a cuchillo «... el octavo día después de la batalla de Navas sesenta mil infieles (?) dentro de los muros de Úbeda...», esta ciudad vuelva a manos musulmanas? ${ }^{14}$. Naturalmente algo

13 Las crónicas musulmanas aportan pocos datos sobre el rango que tuvo úbeda en los primeros tiempos de la reconquista. Sabido es que la dominan los Yamaríes por un tiempo, y que fue en aumento la intolerancia hacia los mozárabes, mientras los moros levantan fuertes murallas. Úbeda, dependiente de Toledo en la división provincial Yusuf el Jehir (746) progresó bastante durante el Califato. Después de la muerte de Almanzor se recrudece la intolerancia contra los cristianos, tomando conciencia del papel de fortín defensivo que le tocaba desempeñar, como lugar de acogida a musulmanes que escapaba de avanzadillas cristianas en su entorno más próximo. Puede verse: M. RUIZ PRIETO, Historia de Úbeda (1909), pp. 14-15; J. PASQUAU GUERRERO, Biografía de Úbeda, Úbeda, 1984, pp. 13-19, y A. CAZABÁN LAGUNA, Apuntes para la historia de Úbeda, Úbeda, 1992 (ed. facsímil), pp. 13-23.

14 Sin duda el año 1212 marca un hito fundamental en el avance cristiano hacia el sur. Después de incursiones anteriores, como la de Fray Fernando Escarza, apoyada por el arzobispado de Toledo y las tropas reales, fueron los días del triunfo de la Santa Cruz en Navas los más decisivos para el futuro de ambos bandos. Caerán sucesivamente Vilches, Baños, Ferraz, Tolosa...; luego tocó la vez a 
fue distinto en el Sur, pasados doscientos años desde la repoblación de Sepúlveda. Entre otras muchas razones porque El Islam era duro rival para cristianos que idealizaban el celibato, al menos teóricamente, y que convertían el oficio de las armas en privilegio de unos pocos, por mucho que no imperasen modelos feudales rígidos.

¿Faltaron nobles, como aventuró Ortega y Gasset, para acelerar el proceso...? Es posible, y de ello se benefició parte de la plebe, ascendida a rango de hidalguía con la urgencia del momento, convertida a la larga en la más pesada losa que inmovilizó a la monarquía. Pero fundamentalmente faltaron hombres, a secas. Una enfermedad que acabó siendo endémica, luego de terminada la Reconquista, y que tantos «desiertos invertebrados" generó.

Se comprende que ahora el desierto-frontera no sea más que un símbolo. Un mito. Es más ¿existió frontera más allá de las murallas de Úbeda desde julio de 1233 ? Se nos antoja acaso aquella frontera como algo artificial, incómodo a ambas partes. Permaneció mucha población musulmana en el lado de la cruz, y, en pos de intereses comunes, se "disimuló" un permanente trasiego de uno a otro lado. Pero claro que quedaba algo siempre presente: miedo y violencia, prontos a estallar cuando algo externo rompía el monótono transcurrir de los días; por mucho que el Rey Santo fuese un modelo de monarca cuasi ideal, conjugadas en él las virtudes cristianas de la piedad y la tolerancia con otras más próximas al que con el paso de los años perfilaría Maquiavelo ${ }^{15}$.

Úbeda. Independientemente de la dosis de lirismo o fantasía que encontremos en los cronistas cristianos para narrar el suceso, y de ciertas imprecisiones puntuales en la fecha exacta (las fuentes alude a su cerco el viernes 20 de julio, y su rendición el lunes 23 ), algo de verdad debe existir en las negociaciones que luego siguieron, ofreciendo los moros comprar su libertad pagando «mil veces mil maravedís de plata al contado...", antes de que, consultado el Papa, los cristianos decidan destruirla, pasando a cuchillo a muchos de sus pobladores. Incapaces sin embargo de repoblarla y defenderla, los cristianos volverán a perder Úbeda. Pero el final de esta frontera mora era ya inminente. Sobre el tema, entre otros: FRANCISCO DE BILCHES, Santos y Santuarios del Obispado de Jaén y Baeza, Madrid, 1636, fl. 130; M. DE JIMENA JURADO, Anales eclesiásticos del Obispado de Jaén, Madrid, 1643, fls. 119-122. (Ed.facsímil, con estudio preliminar de J. Rodríguez Molina, y M.J. Osorio Pérez), Granada, 1991.

15 Hemos abordado el perfil humano del Rey Santo en nuestro trabajo «Úbeda fronteriza y cristiana en la historiografía giennense», Congreso internacional «la frontera oriental nazari como sujeto histórico", Murcia, 1994 (en prensa). de modo más monográfico: A. TARIFA FERNÁNDEZ y M.J. PAREJO DELGADO, "Fernando III y su época en la historiografía giennense», Actas IV jornadas de historia militar, Sevilla, 1994, pp. 521-540. Una notable diferencia respecto al cambio de mentalidad el el ocaso del XVIII ofrece el Deán MARTÍNEZ DE MAZAS, limitando rasgos épicos, y tópicos quizás, de la figura de Fernando III, como desaparecen exageradas alusiones a todo lo sobrenatural: Retrato al natural de la Ciudad y término de Jaén, su estado antiguo y moderno, su población, agricultura y comercio, Jaén, 1794 (ed. facsímil, 1975), pp. 97-8. Puede verse: M.J. PAREJO DELGADO, Baeza y Úbeda en la baja Edad Media, Granada, 1988, pp. 28-30; y F. GARCÍA FITZ, “Las conquistas de Andalucía en la cronística castellana del siglo XIII. La mentalidad historiográfica en los relatos de la conquista», $v$ Coloquio internacional medieval de Córdoba, 1988, pp. 51-61. 
En todo caso Úbeda enlaza su destino de ciudad-frontera con el septentrión, y recibe en 1240 el Fuero de Cuenca; noble gesto, que posibilita sea repoblada, con bastante dificultad, por cristianos, sobre todo de Castilla ${ }^{16}$.

Generosidad regia que nadie duda tiene justificación en el riesgo de vivir situaciones fronterizas; Fuero pues de frontera, ideado también aquí para atraer pobladores, para facilitar convivencias y limar asperezas, para premiar al guerrero. Úbeda compró libertades a precio de sangre. $Y$ las mantuvo hasta que fue útil a la monarquía ${ }^{17}$. El sueño acabó cuando cayó Granada. Pero volvamos a la Úbeda-frontera recién conquistada por Fernando III. ¿Qué quedaba allí de lo que un día las tropas de Tarif encontraron? ¿Valdría la pena acaso dar la voz por un momento a viejos cronistas del pasado?:

“... y trataron (Tarif y Muza) en particular sobre todo lo que convenía para proseguir y acabar la conquista... y se resolvieron de tomar la vía de Castilla... y comenzaron a marchar por la rivera de un rio caudaloso (que)... es llamado de los moradores chistianos de aquellas tierras Betis... y guiaron su camino azia la mano izquierda, y llegaron a una ciudad pequeña, llamada por propio nombre en español Úbeda... y habiéndola cercado, sus moradores, de buena conformidad, sin hazer ninguna resistencia, abrieron las puertas..." ${ }^{18}$.

«... era Úbeda plaza fuerte, pertrechada con gente y municiones, como frontera que era de Baeza... más volviendo la primavera, y el Rey Santo a la conquista... cercó segunda vez a úbeda, y la combatió por tantas partes y con tal brío, que desmayó el orgullo de los moros, y se vieron forzados a entregar luego la ciudad... y si bien no se dice el modo, se puede entender haver sido el mismo que en las ziudades grandes, pues lo era Úbeda... ${ }^{19}$.

16 M. PESET y J. GUTIÉRREZ CUADRADO, El Fuero de Úbeda (estudio preliminar), Valencia, 1979, pp. 156-57. J. RODRÍGUEZ MOLINA, «Las órdenes militares de Calatrava y Santiago en el alto Guadalquivir (ss. XIII al XIV)», CEM, Granada, 1974, pp. 70 y ss.

17 J. HIGUERAS MALDONADO, Documentos latinos de Úbeda, I.E.G., Jaén, 1975. Doc. 1, pp. 15-20, y doc. 3, pp. 33-37; PESET y GUTIÉRREZ, Op. cit., pp. 363-70. La proximidad a la frontera tuvo, entre otros inconvenientes, el peligro de cautividad. El destino de los cautivos era la venta en almoneda, cotizándose entre 12-17 doblas. Esta venta de cautivos pasa por la pluma de los cronistas del XVII con bastante frecuencia para justificar la reconquista y repoblación cristiana. Puede verse al respecto A. LINAGE CONDE y A. TARIFA FERNÁNDEZ, «Mentalidad, guerra y religión en la obra de Francisco de Bilches: una visión hagiográfica de la frontera hispano-musulmana", Actas Congreso internacional: "La sociedad de la frontera", Alcalá la Real, 1995 (en prensa). Precisamente el Condestable de Castilla Ruy López Dávalos, natural de Úbeda, fue hecho prisionero por los musulmanes en 1379. En casos de este tipo se recurría al canje con otro personaje importante. En GUERRERO NAVARRETE, Proceso y sentencia contra Ruy López Dávalos, I.E.G., Jaén, 1982, p. 9.

18 A. ABENTARIQUE TARIF, Pérdida y conquista de España (763), Libro I, Cap. XIV, fls. 63-64, Obra apócrifa del que se declara su traductor, Miguel de Luna, Granada, 1589.

19 F. BILCHES, Op. cit., pp. 129-30. 
¿Qué encontramos entre aquella aldea visigoda que encontraría Tarif, y esta gran urbe musulmana que describe el padre Bilches? Admitidas todas las reservas que puedan hacerse a las fuentes ${ }^{20}$, entre ambas situaciones media un abismo. Y no podemos simplificar alegando sólo cuestiones cronológicas. Progresó espectacularmente con los musulmanes por ser frontera; como cimentó luego ese auge, tras la conquista cristiana, por seguir siéndolo, ahora al amparo del Fuero.

Superadas las primeras dificultades para establecer sus límites municipales, especialmente tensas con Baeza y las Órdenes de Santiago y Calatrava, los «Señores» del Fuero de Úbeda, primeros guerreros-repobladores cristianos, se agarran con fuerza a los privilegios. Son el germen de una oligarquía violenta, envidiosa, díscola, que hará derramar sangre en las calles, cuando escaseen ya las cabezas de moros rebeldes. Pequeñas familias hidalgas, con ínsulas de grandeza, exenta de impuestos, excepto para mantener torres y murallas a su costa. $Y$ dispuestas siempre a la guerra. Serán a la postre su nobleza, afianzada de modo firme tras la Sentencia arbitraria de 1446, hasta arrancar a la Corona el reconocimiento postrero de no pechar, a no ser con el simbólico gesto de 5 maravedís. Ellos son «frontera» por antonomasia. Pero también el "desierto" del Sur... porque ya dijimos que desiertos hay muchos. Ellos hicieron posible vivir en Úbeda sin dominio musulmán. Ellos hicieron también que «vivir» en Úbeda fuera muy difícil. Difícil para los "moradores», "siervos", «jornaleros" y "mancebos». Para "hortelanos» y "pastores"..., "paniaguados" todos. Más aún para la comunidad mudéjar, siempre laboriosos, pobres entre los pobres, quizás sólo por eso tolerados. Insoportable en fin para aquella importante comunidad judía, envilecida en tratos artesanales y comerciales, que a duras penas sobrevivió tras los muros del Alcázar en los años de hambre hasta su expulsión.

Cierto que Úbeda progresa como ciudad-frontera, pese a las continuadas banderías de la nobleza. Pero desde 1233 hasta que el avance contra el Reino de Granada se intensifica, la ciudad ve nacer y morir muchas esperanzas, siempre en pie de guerra. Contribuye activamente en la conquista de Córdoba. Los Messias, Dábalos, Tráperas, Porceles, Sanmartines, Arandas, Orozco..., entre otros linajes, levantan a su costa torres, y «La ciudad con el común hizo las murallas todas, $\backslash$ con las torres que faltaban, $\backslash$ con sus ayudas y sobras $\backslash$ Está muy fortificada.... ${ }^{21}$. Desde Úbeda, con apoyo de los maestres de las Órdenes militares, parte el infante don Pedro, en 1313, para tomar el castillo de Alicún. Más tarde el de Belmez y Tíscar, Siles. Nobles de Úbeda están en

20 La obra del morisco granadino Miguel de Luna, intérprete de arábigo al servicio de Felipe II, bebe de viejas crónicas musulmanas y cristianas. Traducida varias veces, pasó del éxito a la denostación. Pese a todo conviene volver a ella más serenamente. Sobre el tema puede verse el trabajo de F. MARQUÉS DE VILLANUEVA, "La voluntad de leyenda de Miguel de Luna», en Revista de Filología Hispánica, T. XXX, 1981 ( $\mathrm{n}^{\circ}$ 2), pp. 359-95. También D. CABANELLAS RODRíGUEZ, El morisco granadino Alonso del Castillo, Granada, 1965. La mentalidad de Bilches, un jesuita baezano hijo de la época, no aporta ninguna sorpresa al lector. Hemos tocado el tema en nuestro trabajo "Mentalidad, guerra y religión...», Op. cit.

21 Forma parte del poema atribuido por algunos al ubetense Jorge de Mercado, en el que se describe el proceso de fortificación y defensa de Úbeda tras su definitiva conquísta. En A. CAZABÁN LAGUNA, Apuntes para la historia de Úbeda (1887), Ed. facsímil, Úbeda, 1992, pp. 40-44. 
la batalla del Salado, y en la toma de Algeciras. Luego será Enrique Il quien premie a sus nobles por la fidelidad a su causa, en años turbulentos de guerras civiles, cuando Pedro I de Castilla «... fiso destruir la ciudad de Úbeda con los moros...". Pero las cosas van cambiando desde que cae Huelma, cuando el término de Úbeda ya queda en retaguardia ${ }^{22}$.

Con la toma de Granada, cansada Úbeda de aportar hombres, trigo y dinero a la Corona, sus privilegios, como ciudad de fuero de frontera, tienen ya los días contados. Precisamente entonces cerraran definitivamente las casas de sus barrios judíos. Todo un símbolo ${ }^{23}$.

Así entramos en el más temido de los desiertos: el mental. Fue éste el que alejó a Úbeda, como a los demás pueblos de España de la modernidad. El que nos invertebró acaso para siempre ¿y no es peor que el estratégico del Duero? ¿y no valdría la pena debatir sobre la pervivencia de esa frontera-desierto hoy, 700 años después...?

Aunque esta ciudad prospere en el XVI, un siglo "corto", sería discutible afirmar que comenzó para Úbeda una «Edad de Oro», después de que en 1507 el corregidor Gil de Mogollón aprovecha las luchas de bandos para derribar parte de su alcázar, un signo ya inútil de independencia, molesto a la monarquía. En todo caso se cambió libertad por prosperidad ${ }^{24}$. Acaso no sabían que, como dijo Domínguez Ortiz, «las épocas de plenitud son transitorias «. Sin duda más transitorias cuando se barren fronteras que no son desiertos. Cuando desaparecen las Extremaduras.

Sepúlveda, Extremadura primera. Úbeda, ya en la postrera. Allí nos podría servir como emblema su Fuero. Aquí perdido el suyo, como se perdieron los cuadernos de repartimiento, nos quedan todavía bastantes casas judías en pie, desconocidas y silenciadas de forma increíble para la macrohistoria.

Hoy, en un congreso de Fronteras, ¿habría que pedir a los más sabios que recuperasen la costumbre de indagar en el detalle de la historia local? Suele ser ejercicio incomodo, sobre todo porque cuando aplicamos la lupa a la microhistoria descubrimos que conviene usar anteojos, como los de Quevedo, con más frecuencia.

Creemos que la «invertebración» de España, en el sentido más genérico, acaso perdura porque lo hacen los desiertos mentales. Que no son generalmente las fronte-

22 Tocamos el tema en el estudio introductorio de Úbeda en 1752, según las Respuestas Generales del Catastro de Ensenada, Tabapress, Madrid, 1994, pp. 14 y ss. M.A. LADERO QUESADA, Los mudéjares de Castilla en la Baja Edad Media, H.I.D., Sevilla, 1978, y La Orden de Santiago en Andalucía. Bienes, rentas y vasallos a finales del siglo XV, Sevilla, 1975, y J. RODRÍGUEZ MOLINA, Las Órdenes militares de Calatrava y Santiago en el alto Guadalquivir, Granada, 1974, pp. 70 y ss.

23 Vale la pena mencionar el encomiable esfuerzo de recuperación y mantenimiento de los barrios judíos ubetenses que viene realizando desde hace años don José Ángel Almagro Alises. La historia hablará de su solitaria y tenaz labor en este ámbito.

24 Pedro Mártir de Anglería escribió por entonces al conde de Tendilla: «... me cuentas como en una novedad que en Úbeda todo anda revuelto, que entre sí se destrozan y aniquilan con mutuas carnicerías los dos partidos, el de Molina y el de La Cueva...". ¿Entraba la ciudad en lo que se ha llamado su gran siglo? Puede verse: E. TORAL PEÑARANDA, Úbeda (1442-1590), Jaén, 1975, p. XXXV; H. KENINSTON, Francisco de los Cobos, Secretario de Carlos V, Madrid, 1980, pp. 2-6, y PAREJO D. y TARIFA FERNÁNDEZ, Estudios sobre Úbeda, Sevilla, 1991, pp. 31-35. 
ras desiertos, pero sí desiertos todas las fronteras que se alzan violentamente. Por ello entre Úbeda y Sepúlveda parecen diluirse fronteras. Y es que, como ya apuntamos, marcadas las diferencias de ambas situaciones en tiempo y espacio, las nociones jurídicas del Fuero sepulvedano, y la presencia de repobladores del norte en el sur, en «fronteras peligrosas", permite encontrar cierto paralelismo entre tanta y tan compleja diversidad enriquecedora de nuestros Reinos Peninsulares. 